\title{
IG \\ pP \\ NORK \\ Divergent: The Time Path of Legacy and Athlete Admissions at Harvard
}

Peter Arcidiacono

J osh Kinsler

Tyler Ransom

Working Paper

2019-081

12/2019

1 HUMAN CAPITAL AND

ECONOMIC OPPORTUNITY

GLOBAL WORKING GROUP
The University of Chicago 1126 E. 59th Street Box 107 Chicago IL 60637 


\title{
Divergent: The Time Path of Legacy and Athlete
} Admissions at Harvard*

\author{
Peter Arcidiacono Josh Kinsler $\quad$ Tyler Ransom \\ Duke University University of Georgia University of Oklahoma \\ NBER \& IZA \\ \& IZA
}

December 6, 2019

\begin{abstract}
Applications to elite US colleges have more than doubled over the past 20 years, with little change in the number of available seats. We examine how this increased competition has affected the admissions advantage that legacies and athletes (LA) receive. Using data on Harvard applications over 18 years, we show that non-legacy, non-athlete (NLNA) applications grew considerably and that LA applications remained flat. Yet, the share of LA admits remained stable, implying substantial increases in admissions advantages for legacies and athletes. We develop a simple theoretical model of university admissions to frame our empirical analysis. Viewed through the lens of the model, stability in the share of LA admits implies that elite colleges treat the number of LA admits and overall admit quality as complements. Our empirical analysis reveals that, if the admissions advantages for LA applicants had been constant throughout this period, there would have been a large increase in the number of minority admits.
\end{abstract}

\footnotetext{
${ }^{*}$ We are grateful to Bocar Ba, Tom Nechyba, and Jimmy Roberts for helpful comments. Peter Arcidiacono served as an expert witness for Students for Fair Admissions, Inc. (SFFA) in the SFFA v. Harvard case. SFFA is not funding his work on this paper. Josh Kinsler worked as a consultant for SFFA in the SFFA $v$. Harvard case. SFFA is not funding his work on this paper. The views expressed and conclusions reached in this paper are those of the authors; they do not purport to reflect the views of SFFA. To the extent this paper relies on records from the SFFA v. Harvard case, it relies solely on the public records from the case.
} 


\section{Introduction}

Admissions at elite colleges in the US have become increasingly competitive. Application rates have soared with little change in the number of seats available (Smith, 2018). For the Class of 2023, Harvard College received 43,330 applications and only admitted 1,950 (Caldera and Mohammadzadeh, 2019). ${ }^{1}$ As a result of the increased competition for a fixed number of seats, the preferences elite colleges give to specialized applicant groups have received greater scrutiny (Desai, 2018). The college admissions scandal that came to light in early 2019 was especially incendiary, in part because it showed that elite colleges' preference for athletes gives further opportunity to applicants from wealthy backgrounds who may not be as academically qualified as the typical admitted student (Chappell and Kennedy, 2019).

In this paper, we examine how increased competition for spots at elite colleges has affected the admissions outcomes of legacies and athletes. We focus on Harvard applicants for the Classes of 2000 to 2017 where - as a result of the Students for Fair Admissions v. Harvard lawsuit - information on admissions for legacies and athletes (LA) and those who are neither legacies or athletes (NLNA) was unsealed (see Trial Exhibit DX 042). ${ }^{2}$ The overall application trends at Harvard during this time frame parallel the trends in the elite college market, with total applications almost doubling over the period. Yet, the rise in applications to Harvard was driven almost entirely by growth in NLNA applications. Consequently, LA applicants accounted for an increasingly smaller share of the applicant pool, falling from $7.5 \%$ to $4 \%$.

To frame how a university might respond to a substantial increase in NLNA applications, we develop a simple theoretical model of university admissions. We show that if a university views the quality of admitted students and the number of LA admits as substitutes, then increasing NLNA applicants will decrease the number of LA admits. As the NLNA applicant pool expands, Harvard would be willing to reduce the number of LA admits in favor of higher quality NLNA applicants. However, student quality and the number of LA admits could also be complements if, for example, legacy admits boost fundraising and the productivity

\footnotetext{
${ }^{1}$ Class refers to the year applicants would graduate from Harvard if they did so in four years.

${ }^{2}$ Legacy refers to those who have at least one parent who attended Harvard. Admissions information is not separately available for legacy and athlete applicants. As a result, all of the analysis in this paper combines these two categories.
} 
of institutional spending is increasing in student quality. ${ }^{3}$ In this case, the relationship between the number of the NLNA applicants and the number of LA admits is ambiguous. A substantial increase in NLNA applicants can then result in large changes in the admissions rates of NLNA applicants with little change in the admissions rates for LA applicants. This best describes what we observe at Harvard.

Despite the significant drop in the LA applicant share, Harvard data show no time trend in the share of admits who are legacies or athletes. This share has been relatively stable over time at an average of $24 \%$. The large difference in the LA share of applicants and admits reflects the very high admit rates for legacies and athletes, with admit rates ranging from $41 \%$ to $48 \%$ over this period. ${ }^{4}$ For the Class of 2000, admit rates were four times higher for legacies and recruited athletes than for NLNA applicants. But by the Class of 2017, admit rates were nine times higher for legacies and recruited athletes.

While the application and admission patterns we observe are consistent with complementary preferences over LA admits and admit quality, an alternative hypothesis is that NLNA applicants became relatively weaker over time. We provide evidence that this is unlikely. First, Harvard data on applicant SAT scores over this time period show a slight upward trend, implying that the quality of NLNA applicants increased. ${ }^{5}$ Second, we find that matriculation rates for NLNA admits decreased slightly over this time period, but that matriculation rates for LA admits increased by over 10 percentage points from a base of 80\%. The increase in matriculation rates for LA admits suggests that the outside options for LA admits got worse. Increases over time in the admissions advantages LA applicants receive result in relatively lower quality LA admits. LA admits to Harvard are then more likely to accept their Harvard offer since their next best option is declining.

The levels and trends in LA applications and admits suggest that these groups receive a significant and growing admissions advantage at Harvard. Arcidiacono, Kinsler, and Ransom (2019) show that LA applicants are more likely to be white and come from high income

\footnotetext{
${ }^{3}$ See also Cowen (2017) for a more detailed discussion of this point in the popular press.

${ }^{4}$ Admit rates are heterogeneous within this category. Arcidiacono, Kinsler, and Ransom (2019) show, using data from the end of this period, that athletes had admissions rates well over $80 \%$, while legacies' admissions rates were over $30 \%$.

${ }^{5}$ While SAT scores rose overall, this is not the case for African American applicants. See page 26 of litigation Document 415-8 for further detail.
} 
households. However, because of recent policy trends related to affirmative action and financial aid, there is a growing sense that other racial groups and less advantaged households are finally in a position to benefit from legacy preferences. ${ }^{6}$ In the final section of the paper, we investigate whether this intuition has merit and how the increased admission advantage for LA applicants affected the racial distribution of the admitted class over time.

We accomplish this using data on the racial distribution of applicants, admits, and matriculants by LA status over the same time period. The raw numbers show an increasing number of minority LA applicants and admits, consistent with the intuition above. However, the level of white LA applicants and admits remains an order of magnitude larger than the other groups. As a result, an increase in the LA admissions advantage will still tend to predominantly benefit white applicants. Moreover, there was substantial growth in minority NLNA applications over this period such that the white share of NLNA applications declined. Thus, even though a greater number of minority applicants stood to gain from LA preferences, an even larger number of minority NLNA applicants applied. Using information on the ratio of LA/NLNA admit rates and trends in the LA share of applicants by racial/ethnic groups, we show that the increasing LA admissions advantage between the Classes of 2000 and 2017 reduced racial diversity at Harvard.

The favorable treatment that legacies and athletes receive in the admissions process at elite colleges is well documented. In 1990, the Office for Civil Rights (OCR) concluded its investigation of Harvard and revealed that legacies and athletes were admitted at much higher rates than other applicants for the Classes of 1983-1992. Lamb (1993) illustrates that Yale had similar patterns in admit rates over the same time period. A number of books have been written on the topic, including Bowen and Levin (2003), Karabel (2005) and Golden (2006). The general findings from this literature are that elite institutions in the US provide substantial admissions boosts for legacies and athletes. Golden (2006) documents specific ways by which legacies and athletes obtain admission over more academically qualified applicants. Karabel (2005) focuses on the rise of holistic admissions as a means of admitting

\footnotetext{
${ }^{6}$ During the Students for Fair Admissions v. Harvard trial, the Harvard Dean of Admissions testified to this point. When asked whether "...the legacy applicant pool is on average less ethnically diverse than the non-legacy applicant pool?", he responded "At the moment it is, but it's fast changing." See Day 1 Trial Transcript. See also Lattimore (2018) for a discussion in the popular press.
} 
a certain type of student (and one who is not the most academically qualified). Bowen and Levin (2003) focus on the large fraction of athletes and legacies at Ivy League schools and other private, elite universities, and provide recommendations for resolving some of the corresponding issues.

Going beyond simple differences in admit rates, a handful of papers estimate the size of the admissions advantage that legacies and athletes receive. Hurwitz (2011) uses data from the fall of 2007 admissions cycle at thirty private colleges and universities and finds that legacy applicants are three times more likely to be admitted than non-legacy applicants. Arcidiacono, Kinsler, and Ransom (2019) show that, for the Harvard Classes of 2014 to 2019, legacy and athlete applicants are highly advantaged relative to NLNA applicants and receive large admissions preferences. Using admissions data from three elite research universities during the 1983, 1993, and 1997 admissions cycles, Espenshade, Chung, and Walling (2004) estimate the admissions preferences that legacies and athletes receive. Overall, the authors find large admissions preferences for athletes and legacies. In addition, between 1983 and 1997, the admissions advantage for legacies declined, while for athletes it expanded.

We add to this literature by investigating how legacy and athlete admissions advantages at an elite school have changed over time in a more recent period that is characterized by a surge in applicant competition. We show that the admissions advantage for legacies and athletes dramatically increased at Harvard over the 18-year period ending in fall 2012. We also demonstrate that these advantages act to the detriment of minority applicants who are not legacies or athletes.

The rest of the paper proceeds as follows. In Section 2, we present a simple theoretical model of admissions. Section 3 shows the main trends in Harvard applications, admissions, and matriculation. In Section 4, we explain how we separate composition effects in the growth in LA admissions advantages. Section 5 concludes.

\section{A Model of College Admissions}

We begin by considering how changes in the applicant pool affect admissions decisions under different types of university objective functions. Given the tremendous rise in applicants to 
Harvard and other elite institutions, we are particularly interested in how an increase in the number of applicants - and in particular changes in the number of NLNA applicants - affects admissions decisions differently for LA and NLNA applicants.

We model the university as valuing two characteristics in its admitted class: student quality, $x \in \Re^{+}$, and whether the student is a legacy, $s \in\{l, n\}{ }^{7}$ Student quality refers to all attributes which the university values (both observed and unobserved) other than legacy status. In the population of $s$-status students, $x$ is distributed according to a cumulative distribution function $\Phi_{s}(x)$ with a corresponding probability density function $\phi_{s}(x)$. The university receives $N_{l}$ legacy applications and $N_{n}$ non-legacy applications. The university can admit at most $\bar{N}$ students. Consistent with trends in the actual data, we assume that $\bar{N}$ is fixed.

We consider two different ways by which preferences for legacy status can operate, with proofs given in Appendix A. In the first, the university maximizes the sum of $x$ for its admitted students plus an additional term that is an increasing function of the number of admitted legacies. Denote this function as $h(\cdot): \Re^{+} \rightarrow \Re^{+}$whose first derivative is positive and second derivative is negative. Clearly, if the university finds it optimal to admit a legacy (non-legacy) student with index $x^{\prime}$ then it will also be optimal to admit all legacy (non-legacy) students with $x>x^{\prime}$. There is then a cutoff value of $x$ for both legacy and nonlegacy students, $c_{l}$ and $c_{n}$, where students above these cutoffs are admitted. Further, since $h(\cdot)$ is increasing in the number of admitted legacy students, $c_{l}<c_{n}$. We then characterize what happens to the number of legacy admits when the number of non-legacy applicants increases.

Theorem 1 Suppose the university's maximization problem is given by

$$
\begin{array}{r}
\max _{c_{l}, c_{n}} N_{l} \int_{c_{l}} x \phi_{l}(x) d x+N_{n} \int_{c_{n}} x \phi_{n}(x) d x+h\left(N_{l}\left[1-\Phi_{l}\left(c_{l}\right)\right]\right) \\
\text { s.t. } N_{l}\left(1-\Phi_{l}\left(c_{l}\right)\right)+N_{n}\left(1-\Phi_{n}\left(c_{n}\right)\right)=\bar{N} .
\end{array}
$$

If both legacy and non-legacy applicants are admitted, then increasing the number of nonlegacy applicants increases the cutoff for legacy applicants at the solution to the maximization

\footnotetext{
${ }^{7}$ For ease of exposition, throughout the model section we use legacy rather than legacy and athlete.
} 
problem, i.e. $\frac{\partial c_{l}}{\partial N_{n}}>0$. This results in fewer legacy applicants being admitted.

Proof In Appendix A.1.

When the university's preferences are additive in the quality of the student body and a function of the number of legacy admits, an increase in the number of non-legacy applicants results in a decrease in the number of legacy admits. The increased number of non-legacy applicants means that there are more non-legacy applicants of high quality who crowd out some of the legacies who would have been admitted absent the increase in non-legacy applicants.

A second potential objective function for the university is one in which legacy preferences are multiplicative. Namely, the university could instead maximize the sum of $x$ for admitted students times an increasing function of the number of admitted legacies. Just as in the additive preferences case, denote this function as $h(\cdot): \Re^{+} \rightarrow \Re^{+}$whose first derivative is positive and second derivative is negative. As before, the solution to this maximization involves admissions cutoffs $c_{l}$ and $c_{n}$. Under this objective function, an increase in the number of non-legacy applicants may actually increase the number of legacy admits.

Theorem 2 Suppose the university's maximization problem is given by

$$
\begin{array}{r}
\max _{c_{l}, c_{n}}\left(N_{l} \int_{c_{l}} x \phi_{l}(x) d x+N_{n} \int_{c_{n}} x \phi_{n}(x) d x\right) h\left(N_{l}\left[1-\Phi_{l}\left(c_{l}\right)\right]\right) \\
\text { s.t. } N_{l}\left(1-\Phi_{l}\left(c_{l}\right)\right)+N_{n}\left(1-\Phi_{n}\left(c_{n}\right)\right)=\bar{N} .
\end{array}
$$

If both legacy and non-legacy applicants are admitted, then, at the solution to the maximization problem, the sign of $\frac{\partial c_{l}}{\partial N_{n}}$ is determined by the sign of:

$$
h^{\prime}(\cdot) N_{n} \phi_{n}\left(c_{n}\right)\left[c_{n}-\frac{\int_{c_{n}} x \phi_{n}(x) d x}{1-\Phi\left(c_{n}\right)}\right]+h(\cdot)
$$

Proof In Appendix A.2.

The sign of $\frac{\partial c_{l}}{\partial N_{n}}$ is then the sum of two terms. The second term is positive. Now consider the first term. Each of the terms multiplying the term in brackets is positive. What is inside the brackets is negative: as a condition of admission, the cutoff value for non-legacies must 
be less than the expected value of $x$ for admitted non-legacies. The larger in magnitude this term is, the larger the gains are for adding more legacy admits. These gains are tempered by $h^{\prime}(\cdot)$ : when there are already many legacy admits, the curvature of $h(\cdot)$ diminishes the gains from the interaction between the number of legacy admits and the quality of the student body.

In the next section, we show that this second model - where the quality of the student body and the number of legacy admits are complements - best matches the empirical patterns in the data. ${ }^{8}$ As $N_{n}$ rises, the gap between the admissions cutoffs $c_{n}$ and $c_{l}$ expands. In the data this will manifest as an increasing admissions advantage for LA applicants over time. Note that this does not imply that Harvard's admissions preferences are changing, simply that the marginal gain from an additional LA applicant is rising.

The question is why student quality and the number of legacy admits would be complementary. If Harvard is interested in maximizing the intellectual output of its students, then both features of the admitted class are important. Boosting the number of legacy admits enhances Harvard's ability to raise funds for investments in physical capital and human capital in the form of faculty. ${ }^{9}$ The productivity of Harvard's investment is greater the higher the skill level of the students. ${ }^{10}$

A second possibility is related to the demand side of the elite college market. According to Jacob, McCall, and Stange (2018), high ability, high wealth students will demand both academic quality and consumption amenities. One aspect of academic quality is peer quality, while consumption amenities can be purchased more easily with increased donations stemming from additional legacy admits. Athlete admits also fit into this framework since they generate a consumption amenity for the other students in the class.

\footnotetext{
${ }^{8}$ An alternative model that would also fit the data is one where Harvard is constrained to keep the number of athlete and legacy admits fixed over time. It is difficult to motivate why such a constraint would exist, and thus we prefer the model allowing for complementarity in admit quality and the number of legacy admits.

${ }^{9}$ For evidence regarding the link between legacy admissions and giving, see Meer and Rosen (2009) and Meer and Rosen (2010).

${ }^{10}$ Zimmerman (2019) and Riehl (2018) find that the return to attending a high quality college is larger for students from wealthy backgrounds. However, Dale and Krueger (2014) and Zimmerman (2014) find that the returns to college quality are large for low income and historically disadvantaged groups.
} 


\section{Aggregate Trends in Harvard Admissions}

Our theoretical model provides a lens through which we can examine changes in Harvard admissions over time. In this section, we describe how application shares and admission rates for special status applicants have changed over an 18-year period. For the analysis, we rely primarily on Trial Exhibit DX 042. This document lists the number of LA and NLNA applicants, admits, and matriculants by race/ethnicity for the Classes of 2000-2017. We supplement the aggregate admissions data with other documents introduced as evidence (and unsealed) as part of the SFFA v. Harvard trial. All documents we cite are publicly available either at the URL in the bibliography, or on the Public Access to Court Electronic Records (PACER) website at https://www . pacer.gov/.

\subsection{Applications}

The aggregate admissions data reported in Trial Exhibit DX 042 reveal tremendous increases in the number of domestic applicants to Harvard over this time period. However, most of the growth in applications has occurred for non-legacy and non-athlete (NLNA) applicants. Figure 1 shows the growth in domestic applicants relative to the Class of 2000 separately for NLNA applicants and legacy and recruited athlete (LA) applicants. ${ }^{11}$ Over this period, the number of domestic NLNA applicants increased from 14,841 to 27,512 , a rise over $85 \%$. In contrast, domestic LA applicants increased from 989 to 1,094, a boost of only 11\%. The data reported in Trial Exhibit DX 042 do not allow for separate analysis of athlete and legacy applications. However, Document 415-9 indicates that for the Harvard Classes of 2014-2019, legacy applicants outnumbered athlete applicants by approximately three to one. Note that the categories are not mutually exclusive as a legacy can also be a recruited athlete.

An open question is why the number of applications to Harvard increased over this time period. While Harvard made changes to its own admissions and financial aid policies, ${ }^{12}$

\footnotetext{
${ }^{11}$ Appendix Table B1 provides the raw application, admit, and matriculant numbers for domestic NLNA and LA applicants by Harvard graduating class.

${ }^{12}$ First, Harvard eliminated (Class of 2012) and then restored (Class of 2016) their early action admissions program (see Trial Exhibit DX 728; Finder and Arenson, 2006; and Lewin, 2011). Second, Harvard pursued a number of financial aid reforms over this time period, including an affordability initiative for the Class of 2012 (see The Harvard Gazette, 2007; Trial Exhibit DX 728).
} 
looking beyond Harvard it is clear that other elite colleges and universities experienced similar growth. In Appendix Figure B3, we graph the number of applications (Panel (a)) and the growth in applications (Panel (b)) for Harvard and other elite institutions. ${ }^{13}$ The overall trends in applications are very similar, with both Harvard and other elite schools seeing their application totals rise by over $100 \%$ between the Classes of 2005 and 2021 . There are a number of factors that could be driving these broader trends, including: (1) an expanding set of high school graduates; (2) increases in the number of applications conditional on applying to college; and (3) increases in the share of high school graduates that apply. ${ }^{14}$

Interestingly, none of the above explanations for the rise in applications to Harvard is likely to boost LA applications. First, there is simply a smaller population of potential legacy and recruited athlete applicants, making it difficult to expand this group further. Second, legacy and recruited athlete applicants at Harvard tend to come from highly advantaged families. ${ }^{15}$ Historically, these applicants applied to and attended 4-year schools regardless of ability, leaving little scope for additional applications (Belley and Lochner, 2007).

The growth in the NLNA applicant pool could be driven by poorly qualified applicants. However, this does not appear to the case. The aggregate admissions data reported in Trial Exhibit DX 042 also lists the average SAT scores among all applicants and admits over this time period. ${ }^{16}$ As depicted in Appendix Figure B1, the average SAT score in the applicant pool was 692 for the Class of 2000 and rose to 700 for the Class of 2017. This change in the average SAT score over time is likely driven by changes in the NLNA population, since athletes and legacy applicants are a small share of the broader pool.

\footnotetext{
${ }^{13}$ Elite institutions are those 4-year public and private universities that have a 75 th percentile math SAT score greater than or equal to 750 between the years of 2001 and 2017 in the US National Center for Education Statistics' Integrated Postsecondary Education Data System (IPEDS). We drop any school missing more than one year of SAT scores or missing any application totals. The other elite schools (besides Harvard) include: Amherst, Caltech, Carnegie Mellon, Columbia, Cornell, Dartmouth, Duke, Harvey Mudd, Johns Hopkins, MIT, Northwestern, Pomona, Princeton, Rice, Stanford, Swarthmore, Penn, Williams, and Yale. In Appendix Figure B4, we report similar numbers for Ivy League colleges only.

${ }^{14}$ Bound, Hershbein, and Long (2009) examine long-run trends in application behavior from the 1970s to the 2000s. Hoxby (2009) finds that the increase in competition has been concentrated in the top 10 percent of colleges.

${ }^{15}$ See Arcidiacono, Kinsler, and Ransom (2019) for additional details.

${ }^{16}$ We do not have data on SAT score trends by LA or NLNA status.
} 


\subsection{Admissions}

With the growth rate of NLNA applications far surpassing the growth rate of LA applications, the share of applications submitted by legacies and recruited athletes is falling over time. This is reflected in Figure 2(a). The dashed lines show the share of domestic applicants that are legacies and athletes, along with the corresponding linear prediction. The share of domestic applicants who are legacies or athletes fell from a high of over $7 \%$ in 2001 to a low of under $4 \%$ in 2015. More surprising is the pattern for admits shown in the solid lines. While the data is noisy, there is no time trend in the share of domestic admits that are legacies or athletes. The share of admits that are legacies or recruited athletes is consistently over $21 \%$ during this time period. In 2017, the last year of the aggregate data, there were $488 \mathrm{LA}$ admits and 1,094 LA applicants out of a total of 1,837 domestic admits and 28,606 domestic applicants. ${ }^{17}$ Thus, $26.6 \%$ of admits were legacies and athletes despite being only $3.8 \%$ of the applicant pool.

With legacies and athletes becoming a substantially smaller share of the applicant pool and their share of admits showing no time trend, it must the be the case that the LA admit rate relative to the NLNA admit rate has grown. Figure 2(b) shows the ratio of the domestic LA admit rate to the admit rate for domestic NLNA applicants. For the Class of 2000 , legacies and athletes were admitted at a rate of $41 \%$, while NLNA applicants were admitted at a rate of $10 \%$, a ratio of approximately four to one. This ratio has increased dramatically over time, and by the end of the sample period the admit rate for legacies and athletes was over nine times that of NLNA applicants. For the Class of 2017, the admit rate for domestic LA applicants was $45 \%$, while the admit rate for domestic NLNA applicants was only $5 \%$. The growing admissions advantage for LA applicants is consistent with an admissions model where student quality and the number of legacy admits are complements.

\subsection{Matriculations}

Another way to illustrate that the rising admit rate ratio between LA and NLNA applicants is the result of an increasing admissions advantage for LA applicants is to examine matric-

\footnotetext{
${ }^{17}$ See Appendix Table B1 for the raw numbers of domestic admits in each year.
} 
ulation rates. If we assume that Harvard values academics and other activities similarly to other colleges and universities, an increase in admissions advantages for LA applicants should imply worse outside options for those who are admitted. In other words, not only are LA admits becoming relatively weaker at Harvard, they will also be relatively weaker at other elite institutions. With worse outside options, the matriculation rates for LA admits should increase. Figure 3 shows that this is indeed the case.

Panel (a) of Figure 3 shows that the matriculation rate for domestic legacies and athletes has grown substantially over this period. Indeed, the share of admitted legacies and athletes who turned down an offer of admission from Harvard fell from $21 \%$ to $10 \%$, or by roughly half. ${ }^{18}$ This stands in stark contrast to the matriculation rates for domestic NLNA admits. The matriculation rate for NLNA admits was $78 \%$ in the Class of 2000 and $77 \%$ in the Class of 2017, meaning that the profile for this group is flat or slightly decreasing. ${ }^{19}$ To the extent that changes in matriculation rates over time reflect changes in outside options relative to the option to attend Harvard, it would appear as though the outside options for legacies and athletes have gotten relatively worse over time.

The matriculation patterns for NLNA and LA admits over time are consistent with the model presented in Section 2. When admit quality and legacy admits are complements, an increase in NLNA applicants will result in the admissions threshold for NLNA applicants rising while the threshold for LA applicants may fall. NLNA admit quality will be higher when the threshold rises, implying better outside options and a decline in the matriculation rate. The increasing competitiveness of the elite college market will tend to dampen the drop in matriculation rates since all schools are becoming more competitive. Alternatively, the quality of legacy admits will fall if the legacy threshold falls, implying worse outside options and higher matriculation rates.

When modeling Harvard's admissions problem, we assumed that the total number of seats available for domestic NLNA and LA applicants, $\bar{N}$, was fixed. Yet, the data suggests that the number of seats available for domestic applicants is actually shrinking. At the same time that domestic NLNA applications soared, competition from international applicants

\footnotetext{
${ }^{18}$ Raw matriculant totals for LA and NLNA applicant groups are presented in Appendix Table B1.

${ }^{19}$ The dip for the Classes of 2012 to 2015 coincides with Harvard eliminating early action for these admissions cycles (see Trial Exhibit DX 728).
} 
also increased. Panel (b) of Figure 3 shows the number of domestic and international matriculants over time. The growth in the number of international matriculants is accompanied by decreases in the number of domestic matriculants. The number of domestic matriculants declined from a total of 1,527 in the Class of 2000 to 1,474 in the Class of 2017. Regressing the number of domestic matriculants on year shows a statistically significant negative trend of 3.6 domestic matriculants per year, on average.

But these losses are concentrated among NLNA matriculants. Between the Class of 2000 and the Class of 2017, the number of domestic NLNA matriculants declined from 1,203 to 1,037. Regressing the number of domestic NLNA matriculants on year shows a statistically significant loss of 5.2 domestic NLNA matriculants a year. In contrast, the number of domestic LA matriculants increased from 324 to 437 over the same period. Thus, not only are domestic NLNA applicants losing out to domestic LA applicants, they are being increasingly squeezed by international applicants.

The evidence presented in this section suggests that, over the past 20 years, Harvard has provided an increasing admissions advantage to legacy and recruited athlete applicants. Historically, these applicants are believed to come from primarily white and economically advantaged households. ${ }^{20}$ However, there have been broad changes to the higher education marketplace in the past half-century that may alter the set of individuals able to benefit from these advantages. The next section explores this idea further by examining how the trend in LA admissions has impacted the racial composition of admits at Harvard.

\section{LA Status and Race}

The representation of minority students at elite American colleges and universities increased in the 1970s, due in part to affirmative action. The children of this earlier generation of minority students now stand to potentially benefit from legacy admissions. ${ }^{21}$ On the other hand, minority students are still under-represented relative to whites among LA applicants

\footnotetext{
${ }^{20}$ Arcidiacono, Kinsler, and Ransom (2019) document that LA applicants are more than two-thirds white and come from families with much higher incomes.

${ }^{21}$ Howell and Turner (2004) explore this idea using admissions data and trends from the University of Virginia. At the time of writing in 2002, they projected a three-fold increase in the share of legacy applicants that are African American by 2025.
} 
and may therefore be hurt by increased advantages for legacies and athletes. In this section, we examine the impact of these two channels on minority admissions.

\subsection{LA and NLNA Trends by Race}

To investigate whether minorities benefit more from legacy and athlete admissions advantages in the current period relative to 20 years ago, we begin by replicating Panel (a) of Figure 2 for four racial categories of Harvard applicants: Asian American, African American, Hispanic, and white/unknown. ${ }^{22}$ The resulting graphs are presented in Figure 4. Consistent with the overall picture in Figure 2, we see that the LA share of applications is falling over this period for all racial groups other than Asian Americans. ${ }^{23}$

A very different story emerges when we examine trends in the LA share of admits. Figure 2 indicates that the overall share of admits that are legacies and athletes remained flat from 2000 to 2017. In stark contrast, Figure 4 shows that, for all racial groups, the LA share of admits increased. As an example, the LA share of Hispanic admits increased from approximately $3 \%$ in 2000 to $12 \%$ in 2017 . How is it possible that the overall LA share of admits is flat, but that the trend is upward within racial groups? The key feature that explains this result is the declining proportion of white/unknown admits, from $62 \%$ in 2000-2002 to 53\% in 2015-2017. The LA share of white/unknown admits is approximately $35 \%$, while the same share for the other racial groups is between $5 \%$ and $13 \%$. Thus, as the proportion of the admitted class that is non-white grows, the LA share of all admits stays flat despite the fact that, within race, LA admits are becoming more prevalent. When viewed through this lens, it suggests that the admissions advantage for legacy and athlete applicants is probably growing even faster than what Figure 2 indicates.

\footnotetext{
${ }^{22}$ It is important to include in the analysis applicants who fail to report their race, since the patterns over time are quite different for this group. The number of LA and NLNA applicants and admits who fail to report race declined considerably between 2000 and 2017. This is especially true in relative terms since the totals for all other racial categories rose (see Table 1). By including the unknown group with white applicants, we illustrate that the overarching patterns we observe are not being driven by this unique group. One may expect the unknown group to consist primarily of white and Asian American applicants - the only two racial groups who would have an incentive to withhold their race. The composition of the group has likely shifted over time, since the number of Asian American applicants has grown faster than the number of white applicants. The patterns for whites alone would be starker than what our figure indicates. See Figure B2 for additional detail.

${ }^{23}$ For Asian Americans, the LA share of applicants increases, but the levels are small both at the beginning $(1.2 \%)$ and end $(1.6 \%)$ of the period.
} 
A key takeaway from Figure 4 is that all racial groups appear to experience increases in legacy and athlete admissions boosts. Within each racial category, the LA share of admits is growing while the LA share of applicants is falling (with the exception of Asian Americans). However, it is difficult to infer from these pictures whether a growing number of minority students are benefiting from LA preferences. To address this, we provide in Table 1 the raw numbers of LA and NLNA applicants and admits by race, aggregated into three-year windows. The raw data indicate that an increasing number of minority students are in a position to benefit from LA preferences. Between 2000-2002 and 2015-2017, the number of African American, Hispanic, and Asian American LA applicants increased by 42\%, 158\%, and $130 \%$, respectively. The increase in the number of LA admits was more muted, ranging from $35 \%$ for African Americans to $69 \%$ for Hispanics.

While the raw numbers indicate that more minorities are in a position to benefit from increasing LA admissions advantages, they tend to mask two important broader trends. First, despite the recent growth in minority LA applications and admits, the corresponding levels of white LA applicants and admits remain an order of magnitude larger. In the 20152017 period, $68 \%$ of LA applications were from white applicants ( $78 \%$ if we also include applicants who fail to report their race). As a result, when LA admissions advantages increase, white applicants are likely to experience the largest gain. The second broader trend is the huge growth in NLNA applications among minority groups. Between 2000-2002 and 2015-2017, the number of NLNA African American, Hispanic, and Asian American applications increased by $274 \%, 214 \%$, and $112 \%$, respectively. The growth among these groups outstripped growth for whites such that the white share of NLNA applications fell from $43 \%$ to $40 \%{ }^{24}$ Thus, the increased advantages for LA applicants have worked to the detriment of a growing share of minority NLNA applicants.

\footnotetext{
${ }^{24}$ The white/unknown NLNA application share fell from $57 \%$ to $47 \%$ by the end of the period. To calculate the numbers in the main text and this footnote, we also include "Other" and "Nat Am/Nat HI" NLNA applicants in 2000-2002 and 2015-2017.
} 


\subsection{Compositional Effects of LA Access and Preferences}

Between 2000 and 2017, the racial composition of the admitted class at Harvard has been affected by two changes in the admission process related to legacy and athlete applicants. First, the number and share of minority LA applications is growing. This implies a growing share of minority admits, since Harvard employs preferences for LA applicants. Second, LA admissions advantages have expanded over this time period. Since white applicants continue to make up the majority of LA applicants, this expansion will still tend to favor white applicants. In the counterfactuals below, we investigate how each of these channels has affected the LA and racial composition of the admitted class, comparing in particular the changes between 2000-2002 and 2015-2017.

\subsubsection{Counterfactual 1: increases in minority admissions due to increases in LA shares}

Our first counterfactual involves altering the pool of LA applicants. In 2000-2002, the share of LA applicants that were African American, Hispanic, or Asian American was 4.9\%, $2.2 \%$, and $4.6 \%$ respectively. We match these shares in 2015-2017 by reducing the number of African American, Hispanic, or Asian American LA applicants and shifting the excess applicants to the NLNA applicant pool. As a result, we do not change the overall number of minority applicants, we simply shift the relative quantities between the LA and NLNA applicant pool.

Let $r$ indicate race, $r \in\{a, b, h, w\}$; $s$ indicate legacy/athlete status, $s \in\{l, n\}$; and $t$ indicate the first three years of the data or the last three, $t \in\{0,1\}$. Denote $N_{\text {rst }}$ and $A_{r s t}$ as the number of respective applicants and admits who have characteristics $\{r, s\}$ and applied in year $t$. Denote the strength of applicant $i$ in the set $\{r, s, t\}$ - that is, including any admissions advantages from LA status - by $\beta_{r s t}+\epsilon_{i}$. $\beta_{r s t}$ is the average strength of the applicant with characteristics $\{r, s\}$ in year $t$, and $\epsilon_{i}$ represents deviations from the average. Applicants are ordered according to their strength, with Harvard admitting students until its capacity constraint binds.

Assuming that $\epsilon_{i}$ follows a logistic distribution, the average probability of admission for 
someone in the set $\{r, s, t\}, P_{r s t}$, can be expressed in logit form:

$$
P_{r s t}=\frac{\exp \left(\beta_{r s t}\right)}{1+\exp \left(\beta_{r s t}\right)}=\frac{A_{r s t}}{N_{r s t}}
$$

Since we observe the admit rates for each race, legacy/athlete status, and time period combination, we can calculate $\beta_{r s t}$ for all $r, s$, and $t .^{25}$

We now outline a set of assumptions that allows us to recover how the shift in the legacy applicant pool affected enrollment across racial groups. To do this, we first shift down the number of legacy applicants that are of each race - with the exception of whites - such that the share of legacy applicants in $2015-2017$ is the same as in $2000-2002 .{ }^{26}$ Let $N_{w l 1}^{(1)}=N_{w l 1}$. We then choose $N_{r l 1}^{(1)}$ for all $r \neq w$ such that:

$$
\frac{N_{r l 1}^{(1)}}{\sum_{r^{\prime}} N_{r^{\prime} l 1}^{(1)}}=\frac{N_{r l 0}}{\sum_{r^{\prime}} N_{r l 0}}
$$

The number of NLNA applicants of race $r$ is then $N_{r n 1}^{(1)}=N_{r n 1}+N_{r l 1}-N_{r l 1}^{(1)}$.

Next, we assume that the shifting of minority LA applicants to NLNA applicants does not affect the average characteristics of either group. This assumption is likely to be violated: we would expect minority LA applicants to be stronger than minority NLNA applicants as LA applicants come from wealthier households (Arcidiacono, Kinsler, and Ransom, 2019). Hence, shifting some of them to NLNA would raise the average characteristics of NLNAs, leading us to overstate minority gains in admissions from changes in the racial composition of legacies and athletes. However, given the small share of minority applicants who are legacies or athletes, the effect is likely to be small.

With fewer LA applicants, overall admission rates would need to be higher for the same number of students to be admitted. Let $\Delta^{(1)}$ be the rise in the admissions index for all applicants such that the total number of admits is the same as the status quo in period 1.

\footnotetext{
${ }^{25}$ As an example, Table 1 indicates that there are 32,940 white NLNA applicants and 1,641 white NLNA admits in 2015-2017. The observed admit probability for this group is $4.98 \%$. This implies that $\beta_{w n 1}=$ -2.95 .

${ }^{26}$ We also hold fixed the number of LA applicants belonging to all other racial groups and the unknown race group.
} 
The counterfactual probability of admission for $\{r, s, t\}$ is then:

$$
P_{r s 1}^{(1)}=\frac{\exp \left(\beta_{r s 1}+\Delta^{(1)}\right)}{1+\exp \left(\beta_{r s 1}+\Delta^{(1)}\right)}
$$

where $\Delta^{(1)}$ satisfies:

$$
\sum_{r} \sum_{s} N_{r s 1}^{(1)} P_{r s 1}^{(1)}=\sum_{r} \sum_{s} A_{r s 1}
$$

Once we solve for $\Delta^{(1)}$, we can calculate the predicted number of admits for every race and status combination:

$$
A_{r s 1}^{(1)}=N_{r s 1}^{(1)} P_{r s 1}^{(1)}
$$

We can also calculate the share of admits of race $r$ that are legacy/athlete: $A_{r l 1}^{(1)} /\left(\sum_{s} A_{r s 1}^{(1)}\right)$.

The total number of admits and the share of admits that are LA for this counterfactual are reported in the second row of Table 2, with the first row showing the status quo. The number of white admits is significantly higher than the status quo, with all other groups lower, showing that the rise in the share of legacy applicants that are minorities has contributed to more minority admits. Unsurprisingly, the share of minority admits that are LA shrinks relative to the status quo since there are fewer minority LA applicants. For whites, the LA share of admits is relatively constant.

\subsubsection{Counterfactual 2: decreases in minority admissions due to increasing ad- missions advantages for LA applicants}

Weighed against these benefits is the increased admission tip for LA applicants, since LA applicants are disproportionately white. In our second counterfactual, we examine how the increased admissions advantage for LA applicants affected enrollments by race and LA status. Namely, we change the admissions thresholds such that the following two conditions are met:

(i) the overall admit rate ratio between LA and NLNA applicants corresponds to what it was in period 0 , which is $4.15 .^{27}$

\footnotetext{
${ }^{27}$ The same number in period 1 (2015-2017) is 8.15. Implicit in this exercise is that a change in admissions advantage is responsible for the change in the admit rate ratio. As discussed earlier, there do not appear to be significant trends in SAT scores that would suggest a sharp break in the qualifications of the NLNA pool as a whole.
} 
(ii) the total number of admits is the same as in the status quo in period 1 .

The counterfactual admissions probabilities involve changing the admissions threshold differently for LA and NLNA applicants and are are given by:

$$
P_{r s 1}^{(2)}=\frac{\exp \left(\beta_{r s 1}+\Delta_{s}^{(2)}\right)}{1+\exp \left(\beta_{r s 1}+\Delta_{s}^{(2)}\right)} .
$$

$\Delta_{n}^{(2)}$ and $\Delta_{l}^{(2)}$ then solve the admit rate ratio constraint

$$
\frac{\sum_{r} N_{r l 1} P_{r l 1}^{(2)}}{\sum_{r} N_{r l 1}} \frac{\sum_{r} N_{r n 1}}{\sum_{r} N_{r n 1} P_{r n 1}^{(2)}}=4.15
$$

and the capacity constraint

$$
\sum_{r} \sum_{s} N_{r s 1} P_{r s 1}^{(2)}=\sum_{r} \sum_{s} A_{r s 1}
$$

We solve equations (8) and (9) for the two unknowns $\Delta_{n}^{(2)}$ and $\Delta_{l}^{(2)}$. Note that, because the LA/NLNA admit rate ratio has increased substantially between the two periods, $\Delta_{n}^{(2)}$

will be positive and $\Delta_{l}^{(2)}$ will be negative. A lower admissions threshold for LA applicants is consistent with the model we presented in section 2.

The third row of Table 2 shows the results from this counterfactual. Relative to the status quo, we see a $7 \%$ drop in the number of white admits, and an increase of $6 \%, 7 \%$, and 7\% in the African American, Hispanic, and Asian American number of admits, respectively. Within race, the LA share of admits falls dramatically. For whites, the LA share falls by $38 \%$, and for each minority group the LA share falls by at least $44 \%$. The expansion of admission advantages for LA applicants has therefore led to a large increase in not only the number of the LA admits but also the number of white admits.

\subsubsection{Counterfactual 3: net changes in minority admissions from the two chan- nels}

In our final counterfactual, we shift both the minority share of LA applicants as well as the LA/NLNA admit ratio to what it was in 2000-2002, combining the first two counterfactuals. 
Namely, we set the number of applicants in each race and status combination to the level it was in the first counterfactual, $N_{r s 1}^{(3)}=N_{r s 1}^{(1)}$ for all $\{r, s\}$. Next, we solve (8) and (9) by substituting $N_{r l 1}^{(3)}$ for $N_{r l 1}$. Defining $P_{r s 1}^{(3)}$ as

$$
P_{r s 1}^{(3)}=\frac{\exp \left(\beta_{r s 1}+\Delta_{s}^{(3)}\right)}{1+\exp \left(\beta_{r s 1}+\Delta_{s}^{(3)}\right)},
$$

our two equations are then:

$$
\frac{\sum_{r} N_{r l 1}^{(3)} P_{r l 1}^{(3)}}{\sum_{r} N_{r l 1}^{(3)}} \frac{\sum_{r} N_{r n 1}^{(3)}}{\sum_{r} N_{r n 1}^{(3)} P_{r n 1}^{(3)}}=4.15
$$

and the capacity constraint

$$
\sum_{r} \sum_{s} N_{r s 1}^{(3)} P_{r s 1}^{(3)}=\sum_{r} \sum_{s} A_{r s 1}
$$

where we solve for $\Delta_{n}^{(3)}$ and $\Delta_{l}^{(3)}$.

The last row of Table 2 shows that making both adjustments results in higher minority enrollments. That is, the gains from a higher presence of minority legacy applicants are more than offset by the losses associated with higher admissions advantage for LA applicants. For example, the number of African Americans admits would have been 6\% higher in 2015-2017 if both LA preferences and the African American share of LA applicants were fixed at their 2000-2002 levels.

\section{Conclusion}

Admissions to elite colleges and universities have become increasingly competitive. At Harvard, admit rates are now less than 5\%. Yet, some groups have been relatively immune from these competitive forces. Despite representing an increasingly smaller share of the applicant pool, the share of Harvard admits who are legacies or athletes has been remarkably stable over time. Over the course of the 18 years we analyze, legacies and athletes moved from being four times more likely to be admitted as their non-legacy, non-athlete counterparts to nine 
times more likely to be admitted. Given the accompanying rise in applicant test scores and the increase in legacy and athlete matriculation rates, the evidence strongly suggests that the admissions advantages legacies and athletes have at Harvard are growing. This growth can be explained by a model of admissions where the quality of the student body and the number of legacies and athletes are complements in the university's objective function.

Over the course of our time period, the share of LA applicants and admits who are minorities increased. However, LA applicants and admits are still disproportionately white compared to NLNA applicants and admits. So while the number of minority admits have increased as a result of a higher representation among legacies and athletes, we show that these increases are more than offset by the rise in advantages given to LA applicants.

The increasing admissions advantage for legacies and athletes at Harvard is in part the result of enormous growth in NLNA applications with no commensurate increase in available seats. One approach to lessen these advantages would be to expand enrollment. A number of economists have advocated for this, claiming that a reduction in applicant competition would reduce tensions around legacy and athlete admissions. ${ }^{28}$ Thus far, Harvard and other elite institutions have shown little willingness to expand. According to DeSilver (2019), admissions at the most selective universities, have actually fallen between 2002 and $2017 .{ }^{29}$ As a result, the controversy over legacy and athlete admissions will likely continue unless significant changes are made to admissions policies.

\footnotetext{
${ }^{28}$ See Cowen (2018), Smith (2018) and Wermund (2018) for examples.

${ }^{29}$ Recently, the U.S. News $\&$ World Report decided to eliminate a school's acceptance rate when developing its Best Colleges rankings, reducing at least one incentive to keep admissions low. The rankings methodology of U.S. News 83 World Report is described at https://www.usnews.com/education/best-colleges/ articles/how-us-news-calculated-the-rankings.
} 


\section{References}

Arcidiacono, Peter, Josh Kinsler, and Tyler Ransom. 2019. "Legacy and Athlete Preferences at Harvard." Working paper, Duke University.

Belley, Philippe and Lance Lochner. 2007. "The Changing Role of Family Income and Ability in Determining Educational Achievement." Journal of Human Capital 1 (1):37-89.

Bound, John, Brad Hershbein, and Bridget Terry Long. 2009. "Playing the Admissions Game: Student Reactions to Increasing College Competition." Journal of Economic Perspectives 23 (4):119-146.

Bowen, William G. and Sarah A. Levin. 2003. Reclaiming the Game: College Sports and Educational Values. Princeton, New Jersey: Princeton University Press.

Caldera, Camille G. and Sahar M. Mohammadzadeh. 2019. "Record-Low 4.5 Percent of Harvard College Applicants Accepted to Class of 2023." The Harvard Crimson URL https://www . thecrimson. com/article/2019/3/29/2023-admit-numbers/. Accessed June 25, 2019.

Chappell, Bill and Merrit Kennedy. 2019. "U.S. Charges Dozens Of Parents, Coaches In Massive College Admissions Scandal." NPR URL https://www.npr.org/2019/03/12/702539140/ u-s-accuses-actresses-others-of-fraud-in-wide-college-admissions-scandal. Accessed March 23, 2019.

Cowen, "Legacy Students Make Harvard's Finances Work." Bloomberg URL https://www.bloombergquint.com/view/ legacy-students-make-harvard-s-finances-work. Accessed April 26, 2019.

. 2018. "Let Harvard Be Harvard, Only Bigger." Bloomberg URL https://www.bloomberg.com/opinion/articles/2018-11-01/ let-harvard-be-harvard-only-bigger. Accessed August 2, 2019.

Dale, Stacy Berg and Alan B. Krueger. 2014. "Estimating the Effects of College Characteristics over the Career Using Administrative Earnings Data." Journal of Human Resources 42 (2):323-358.

Day 1 Trial Transcript. 2018. In Students for Fair Admissions, Inc. v. President and Fellows of Harvard College et al. Civil Action No. 14-14176-ADB (D. Mass). URL https://github.com/tyleransom/SFFAvHarvard-Docs/blob/master/ TrialTranscripts/20181015-Day-1.pdf.

Desai, Saahil. 2018. "College Sports are Affirmative Action for Rich White Students." The Atlantic URL https://www.theatlantic.com/education/archive/2018/ 10/college-sports-benefits-white-students/573688/. Accessed June 25, 2019. 
DeSilver, Drew. 2019. "A Majority of U.S. Colleges Admit Most Students Who Apply." Report, Pew Research Center. URL https://www.pewresearch.org/fact-tank/2019/ 04/09/a-majority-of-u-s-colleges-admit-most-students-who-apply/.

Document 415-8. 2017. In Students for Fair Admissions, Inc. v. President and Fellows of Harvard College et al. Civil Action No. 14-14176-ADB (D. Mass). URL https://docs.justia.com/cases/federal/district-courts/massachusetts/madce/ 1:2014cv14176/165519/415/1.html. Plaintiff Expert Witness Opening Report.

Document 415-9. 2018. In Students for Fair Admissions, Inc. v. President and Fellows of Harvard College et al. Civil Action No. 14-14176-ADB (D. Mass). URL https://docs . justia.com/cases/federal/district-courts/massachusetts/madce/ 1:2014cv14176/165519/415/2.html. Plaintiff Expert Witness Rebuttal Report.

Espenshade, Thomas J., Chang Y. Chung, and Joan L. Walling. 2004. "Admission Preferences for Minority Students, Athletes, and Legacies at Elite Universities." Social Science Quarterly 85 (5):1422-1446.

Finder, Alan and Karen W. Arenson. 2006. "Harvard Ends Early Admission." The New York Times URL https://www. nytimes .com/2006/09/12/education/12harvard.html. Accessed May 29, 2019.

Golden, Daniel. 2006. The Price of Admission: How America's Ruling Class Buys Its Way into Elite Colleges - and Who Gets Left Outside the Gates. New York: Crown Publishers.

Howell, Cameron and Sarah E. Turner. 2004. "Legacies in Black and White: The Racial Composition of the Legacy Pool." Research in Higher Education 45 (4):325-351.

Hoxby, Caroline M. 2009. "The Changing Selectivity of American Colleges." Journal of Economic Perspectives 23 (4):95-118.

Hurwitz, Michael. 2011. "The Impact of Legacy Status on Undergraduate Admissions at Elite Colleges and Universities." Economics of Education Review 30 (3):480-492.

Jacob, Brian, Brian McCall, and Kevin Stange. 2018. "College as Country Club: Do Colleges Cater to Students' Preferences for Consumption?" Journal of Labor Economics 36 (2):309-348.

Karabel, Jerome. 2005. The Chosen: The Hidden History of Admission and Exclusion at Harvard, Yale, and Princeton. New York: Houghton Mifflin.

Lamb, John D. 1993. "The Real Affirmative Action Babies: Legacy Preference at Harvard and Yale." Columbia Journal of Law and Social Problems 26 (3):491-521.

Lattimore, Ashton. 2018. "Ending legacy admissions is the right thing to do. But for black alums, it stings." The Washington Post URL https://www.washingtonpost. com/outlook/2018/08/06/aaa7db6e-968d-11e8-80e1-00e80e1fdf43_story.html? noredirect=on\&utm_term=.8a353bcfa2c9. Accessed May 15, 2019. 
Lewin, Tamar. 2011. "Harvard and Princeton Restore Early Admission." The New York Times URL https://www.nytimes.com/2011/02/25/education/25admissions.html. Accessed May 29, 2019.

Meer, Jonathan and Harvey S. Rosen. 2009. "Altruism and the Child Cycle of Alumni Donations." American Economic Journal: Economic Policy 1 (1):258-286. 658.

Riehl, Evan. 2018. "Fairness in College Admission Exams: From Test Score Gaps to Earnings Inequality." Working paper, Cornell University.

Smith, Noah. 2018. "Harvard Doing America's Best Students No Favors." Bloomberg URL https://www.bloomberg.com/opinion/articles/2018-06-28/ harvard-and-top-private-schools-should-increase-admissions-a-lot. Accessed June 25, 2019.

The Harvard Gazette. 2007. "Harvard Announces Sweeping Middle-income Initiative." The Harvard Gazette URL https: //news .harvard .edu/gazette/story/2007/12/ harvard-announces-sweeping-middle-income-initiative/. Accessed May 29, 2019.

Trial Exhibit DX 042. 2018. In Students for Fair Admissions, Inc. v. President and Fellows of Harvard College et al. Civil Action No. 14-14176-ADB (D. Mass). URL https://github . com/tyleransom/SFFAvHarvard-Docs/blob/master/TrialExhibits/D042.pdf. Demographic Breakdown of Applicants, Admits, and Matriculants.

Trial Exhibit DX 728. 2018. In Students for Fair Admissions, Inc. v. President and Fellows of Harvard College et al. Civil Action No. 14-14176-ADB (D. Mass). URL https://github. com/tyleransom/SFFAvHarvard-Docs/blob/master/TrialExhibits/D728.pdf. Share of applicants by race before and after changes to early admission policy.

Wermund, Benjamin. 2018. "Should Harvard double its enrollment?" Politico URL https://www.politico.com/newsletters/morning-education/2018/06/19/ should-harvard-double-its-enrollment-258181. Accessed June 26, 2019.

Zimmerman, Seth D. 2014. "The Returns to College Admission for Academically Marginal Students." Journal of Labor Economics 32 (4):711-754.

. 2019. "Elite Colleges and Upward Mobility to Top Jobs and Top Incomes." American Economic Review 109 (1):1-147. 


\section{Figures and Tables}

Figure 1: Growth in LA and NLNA Applications, Classes of 2000-2017

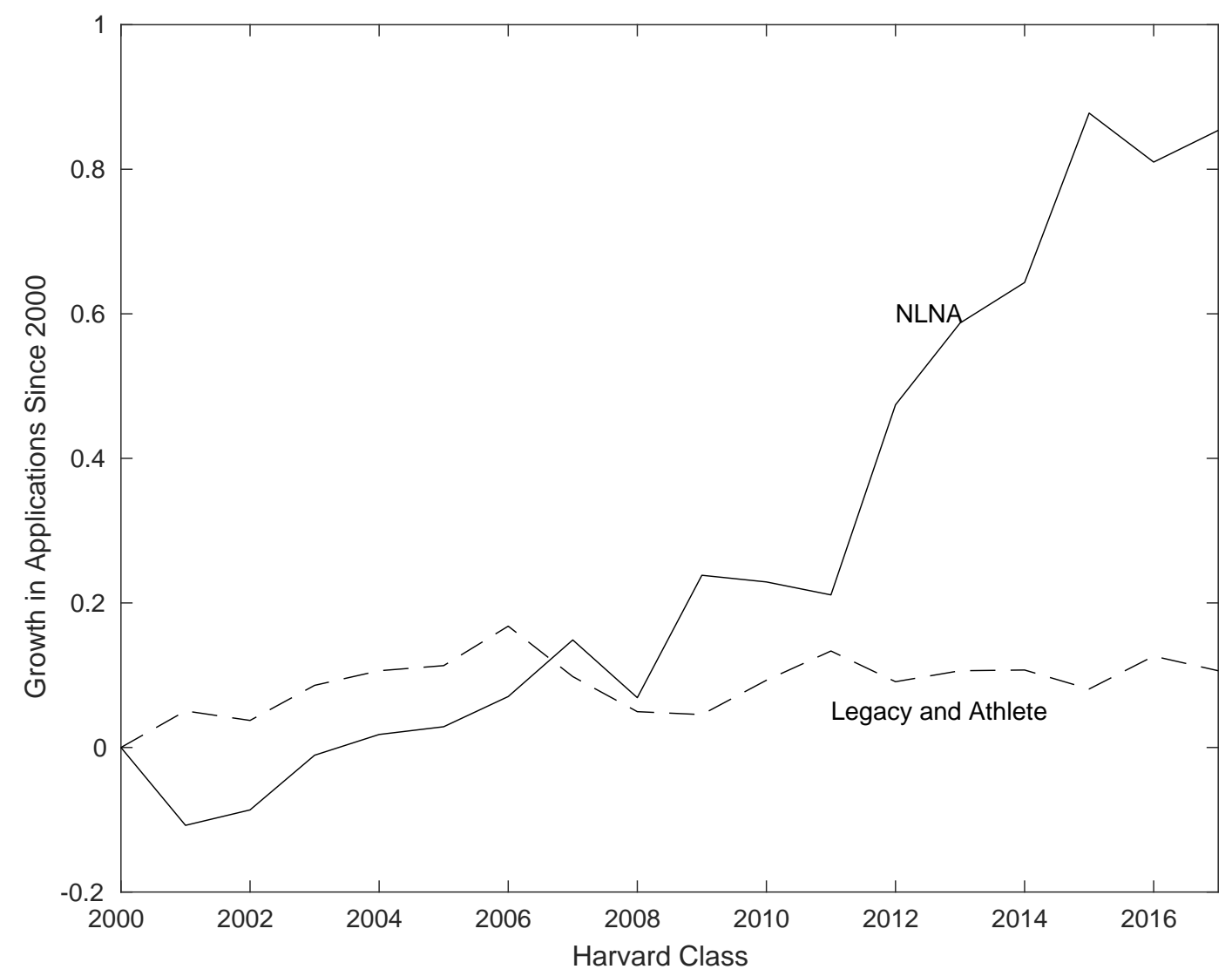

Note: Includes only domestic applicants. Growth is defined as the number of applications in a given year minus the number of applications in the Class of 2000, all divided by the number of applications in the Class of 2000.

Source: Authors' calculations from SFFA v. Harvard Trial Exhibit DX 042. 
Figure 2: Trends in LA Composition and Admissions Rates

(a) Share of Applicants and Admits who are LA

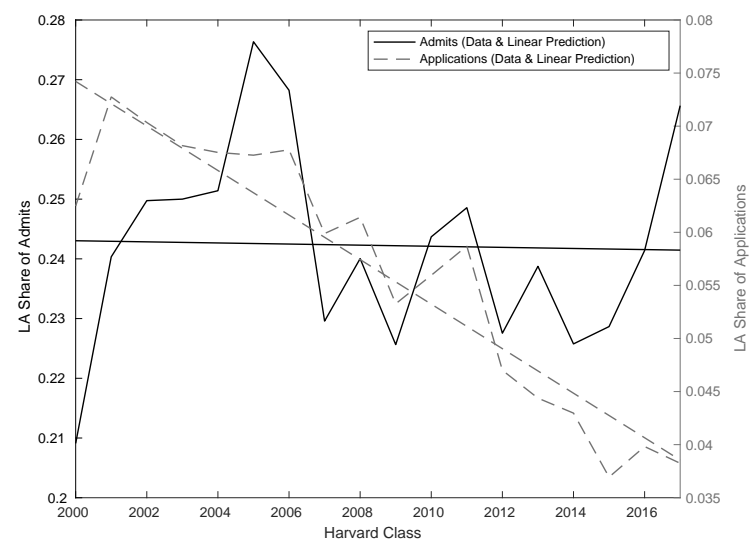

(b) Ratio of LA Admit Rates to NLNA Admit Rates

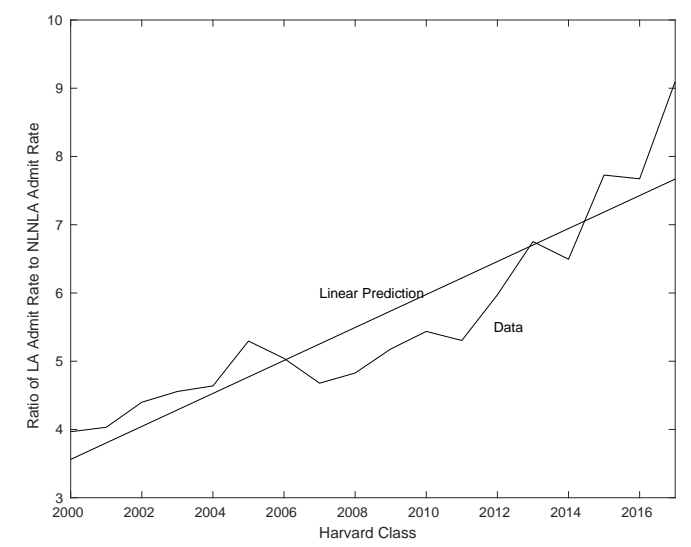

Note: Domestic applicants only.

Source: Authors' calculations from SFFA v. Harvard Trial Exhibit DX 042.

Figure 3: Trends in Matriculation by LA and NLNA, Domestic and International

(a) Matriculation Rates by LA and NLNA Status

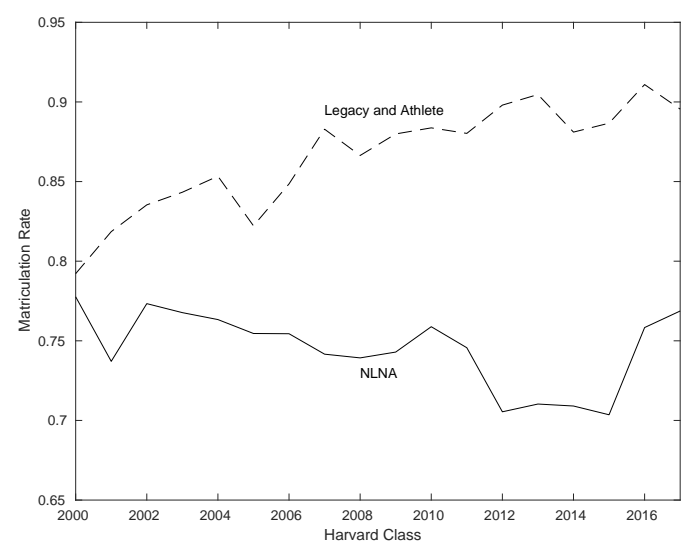

(b) Number of Matriculants by Domestic Status

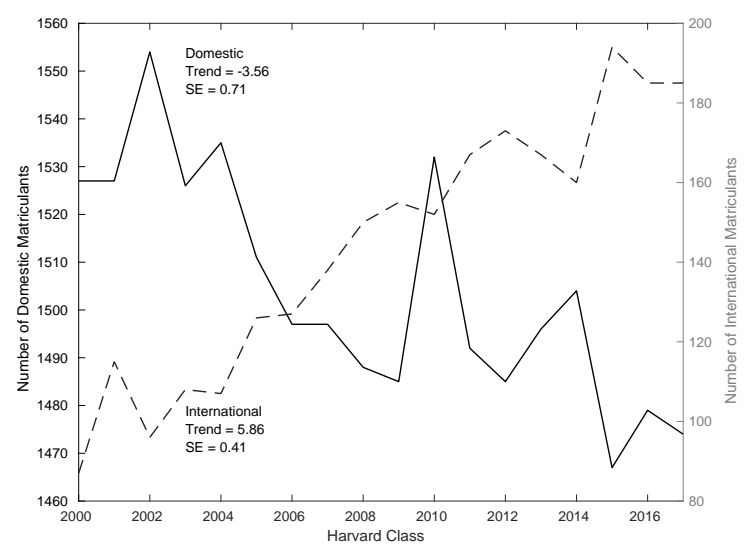

Note: Panel (a) includes domestic applicants only.

Source: Authors' calculations from SFFA v. Harvard Trial Exhibit DX 042. 
Figure 4: Trends in LA Share of Applications and Admits by Race

(a) Asian American

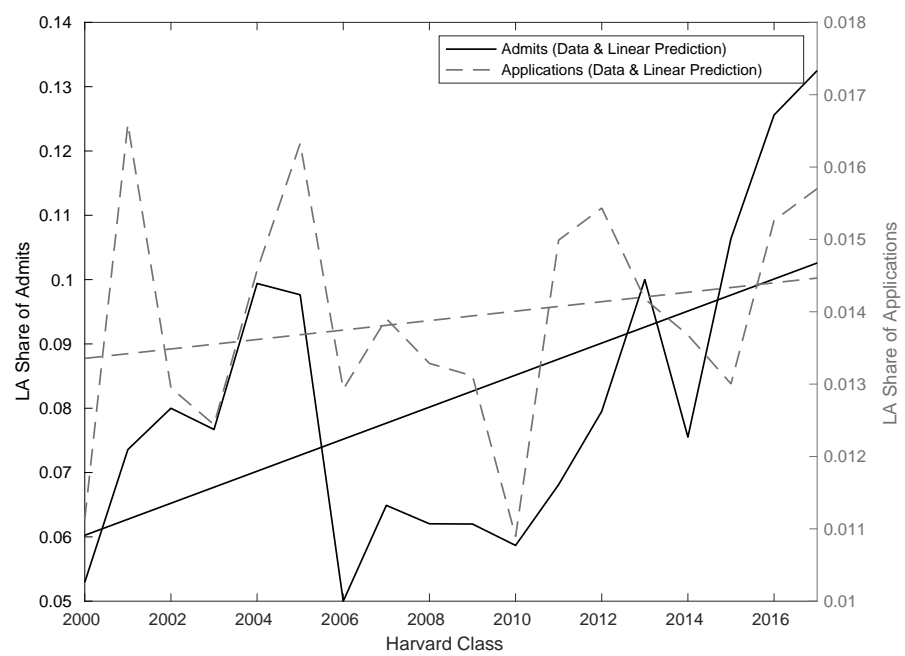

(c) Hispanic

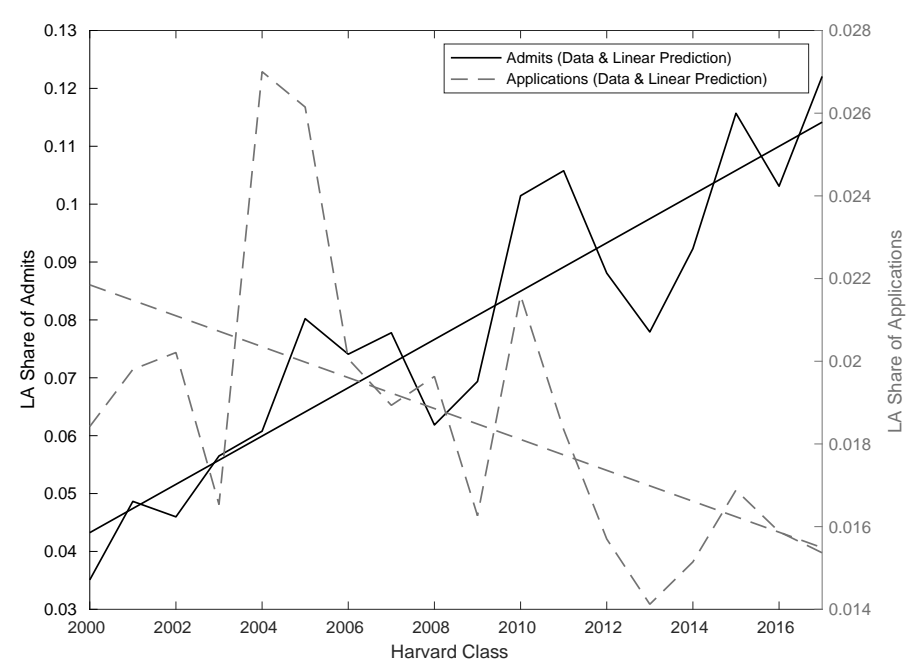

(b) African American

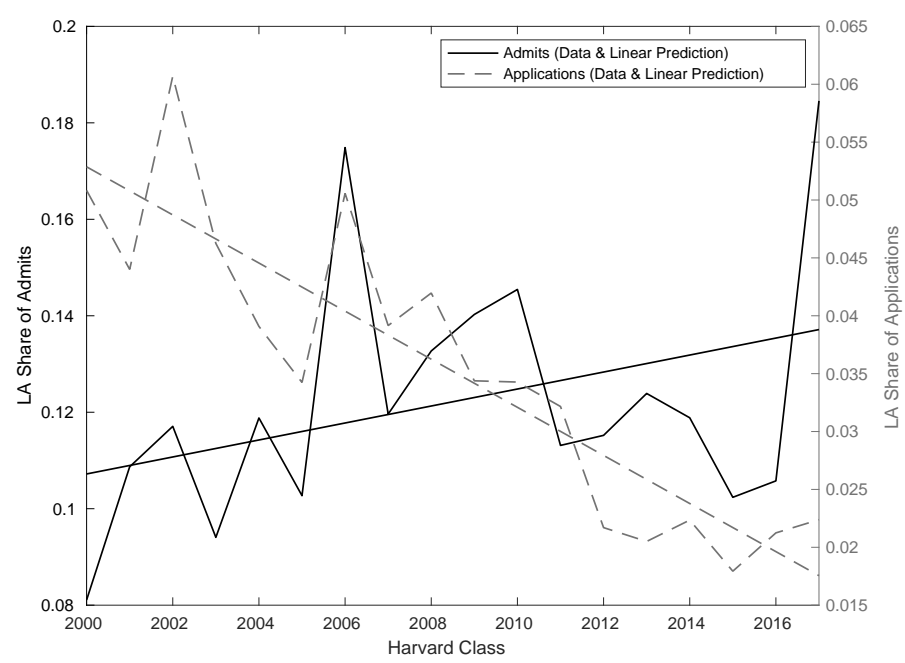

(d) White or Unknown

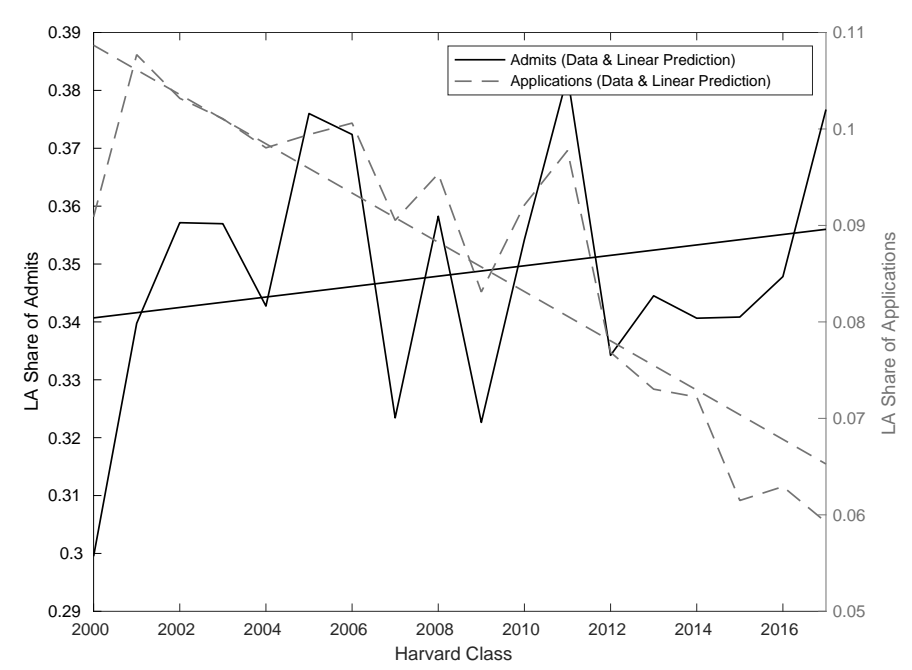


Table 1: Applicants and Admits by Race and Special Status

\begin{tabular}{|c|c|c|c|c|c|c|c|c|c|c|}
\hline \multirow[b]{2}{*}{ Classes } & \multicolumn{5}{|c|}{ Legacy and Athlete } & \multicolumn{5}{|c|}{ Non-Legacy and Non-Athlete } \\
\hline & White & $\begin{array}{c}\text { African } \\
\text { American }\end{array}$ & Hispanic & $\begin{array}{c}\text { Asian } \\
\text { American }\end{array}$ & Unknown & White & $\begin{array}{c}\text { African } \\
\text { American }\end{array}$ & Hispanic & $\begin{array}{c}\text { Asian } \\
\text { American }\end{array}$ & Unknown \\
\hline \multicolumn{11}{|c|}{ Panel A: Applications } \\
\hline $2000-2002$ & 1,952 & 150 & 66 & 139 & 683 & 17,764 & 2,728 & 3,323 & 10,179 & 5,901 \\
\hline $2003-2005$ & 2,184 & 135 & 90 & 158 & 651 & 20,260 & 3,262 & 3,780 & 10,752 & 5,399 \\
\hline $2006-2008$ & 2,367 & 165 & 93 & 171 & 436 & 23,445 & 3,601 & 4,674 & 12,600 & 3,123 \\
\hline $2015-2017$ & 2,243 & 213 & 170 & 320 & 301 & 32,940 & 10,193 & 10,421 & 21,591 & 6,084 \\
\hline \multicolumn{11}{|c|}{ Panel B: Admits } \\
\hline 2000-2002 & 886 & 59 & 23 & 75 & 328 & 1,756 & 515 & 507 & 1,007 & 687 \\
\hline 2003-2005 & 1,033 & 62 & 36 & 88 & 273 & 1,901 & 527 & 509 & 880 & 433 \\
\hline 2006-2008 & 1,055 & 85 & 38 & 64 & 164 & 2,043 & 518 & 498 & 1,018 & 208 \\
\hline
\end{tabular}

Note: Domestic applicants only.

Source: Authors' calculations from SFFA v. Harvard Trial Exhibit DX 042. 
Table 2: Compositional Effects of Increased LA Access and Preferences

\begin{tabular}{|c|c|c|c|c|c|c|c|c|}
\hline & \multicolumn{2}{|c|}{ White } & \multicolumn{2}{|c|}{$\begin{array}{c}\text { African } \\
\text { American }\end{array}$} & \multicolumn{2}{|c|}{ Hispanic } & \multicolumn{2}{|c|}{$\begin{array}{c}\text { Asian } \\
\text { American }\end{array}$} \\
\hline & Admits & LA Share & Admits & LA Share & Admits & LA Share & Admits & LA Share \\
\hline Status Quo & & & & & & & & \\
\hline Expand LA Access \& Admissions Advantage & 2,587 & 0.366 & 695 & 0.131 & 649 & 0.114 & 1,245 & 0.121 \\
\hline Counterfactuals & & & & & & & & \\
\hline 1: Fix Minority LA Access & 2,651 & 0.363 & 688 & 0.090 & 626 & 0.045 & 1,199 & 0.054 \\
\hline 2: Fix LA Admissions Advantage & 2,412 & 0.227 & 738 & 0.072 & 696 & 0.062 & 1,334 & 0.068 \\
\hline 3: Fix Both & 2,448 & 0.229 & 735 & 0.049 & 684 & 0.024 & 1,308 & 0.030 \\
\hline
\end{tabular}

Source: Authors' calculations from data reported in Trial Exhibit DX 042. 


\section{A Proofs of Theorems}

This appendix contains proofs for the two theorems included in the text.

\section{A.1 Proof of Theorem 1}

When the objective function of the university is

$$
\begin{array}{r}
\max _{c_{l}, c_{n}} N_{l} \int_{c_{l}} x \phi_{l}(x) d x+N_{n} \int_{c_{n}} x \phi_{n}(x) d x+h\left(N_{l}\left[1-\Phi_{l}\left(c_{l}\right)\right]\right) \\
\text { s.t. } N_{l}\left(1-\Phi_{l}\left(c_{l}\right)\right)+N_{n}\left(1-\Phi_{n}\left(c_{n}\right)\right)=\bar{N}
\end{array}
$$

with $h(\cdot)>0, h^{\prime}(\cdot)>0, h^{\prime \prime}(\cdot)<0$, the first-order conditions of the Lagrangian are

$$
\begin{array}{r}
-N_{l} c_{l} \phi_{l}\left(c_{l}\right)-h^{\prime}(\cdot) N_{l} \phi_{l}\left(c_{l}\right)-\lambda N_{l} \phi_{l}\left(c_{l}\right)=0 \\
-N_{n} c_{n} \phi_{n}\left(c_{n}\right)-\lambda N_{n} \phi_{n}\left(c_{n}\right)=0 \\
\bar{N}-N_{l}\left(1-\Phi_{l}\left(c_{l}\right)\right)-N_{n}\left(1-\Phi_{n}\left(c_{n}\right)\right)=0
\end{array}
$$

Using the first two equations it is straightforward to see that $c_{n}=c_{l}+h^{\prime}(\cdot)$, or that the cutoff is lower for legacies.

Using this result, we can write the final first-order condition as

$$
\bar{N}-N_{l}\left(1-\Phi_{l}\left(c_{l}\right)\right)-N_{n}\left(1-\Phi_{n}\left(c_{l}+h^{\prime}(\cdot)\right)\right)=0 .
$$

We can take the derivative of both sides with respect to $N_{n}$, exploiting the fact that $c_{l}$ is an implicit function of $N_{n}$, and recover

$$
\frac{\partial c_{l}}{\partial N_{n}}=\frac{1-\Phi_{n}\left(c_{l}+h^{\prime}(\cdot)\right)}{N_{l} \phi_{l}\left(c_{l}\right)+N_{n} \phi_{n}\left(c_{l}+h^{\prime}(\cdot)\right)\left[-h^{\prime \prime}(\cdot) N_{l} \phi_{l}\left(c_{l}\right)\right]}>0
$$

since $h^{\prime \prime}(\cdot)<0$ and all other terms in the expression are positive.

If the cutoff rises, the number of legacy admits will fall, so an increase in $N_{n}$ will result in a decrease in the number of legacy admits. 


\section{A.2 Proof of Theorem 2}

When the objective function of the university is

$$
\begin{array}{r}
\max _{c_{l}, c_{n}}\left(N_{l} \int_{c_{l}} x \phi_{l}(x) d x+N_{n} \int_{c_{n}} x \phi_{n}(x) d x\right) h\left(N_{l}\left[1-\Phi_{l}\left(c_{l}\right)\right]\right) \\
\text { s.t. } N_{l}\left(1-\Phi_{l}\left(c_{l}\right)\right)+N_{n}\left(1-\Phi_{n}\left(c_{n}\right)\right)=\bar{N}
\end{array}
$$

with $h(\cdot)>0, h^{\prime}(\cdot)>0, h^{\prime \prime}(\cdot)<0$, the first-order conditions of the Lagrangian are

$$
\begin{array}{r}
-N_{l} c_{l} \phi_{l}\left(c_{l}\right) h(\cdot)-h^{\prime}(\cdot)\left(N_{l} \phi_{l}\left(c_{l}\right)\right)\left(N_{l} \int_{c_{l}} x \phi_{l}(x) d x+N_{n} \int_{c_{n}} x \phi_{n}(x) d x\right)-\lambda N_{l} \phi_{l}\left(c_{l}\right)=0 \\
-N_{n} c_{n} \phi_{n}\left(c_{n}\right) h(\cdot)-\lambda N_{n} \phi_{n}\left(c_{n}\right)=0 \\
\bar{N}-N_{l}\left(1-\Phi_{l}\left(c_{l}\right)\right)-N_{n}\left(1-\Phi_{n}\left(c_{n}\right)\right)=0
\end{array}
$$

Using the first two equations, we can relate $c_{l}$ and $c_{n}$ according to,

$$
c_{n}-c_{l}=\frac{h^{\prime}(\cdot)\left(N_{l} \int_{c_{l}} x \phi_{l}(x) d x+N_{n} \int_{c_{n}} x \phi_{n}(x) d x\right)}{h(\cdot)} .
$$

Combined with the capacity constraint, this give us two equations in two unknowns. We can rewrite each equation as implicit functions $f(\cdot)$ and $g(\cdot)$, where $N_{n}$ and $N_{l}$ are exogenous arguments and $c_{n}$ and $c_{l}$ are endogenous arguments: ${ }^{30}$

$$
\begin{aligned}
f\left(c_{l}\left(N_{n}, N_{l}\right), c_{n}\left(N_{n}, N_{l}\right), N_{n}, N_{l}\right) & =\left(c_{l}-c_{n}\right) h\left(N_{l}\left(1-\Phi_{l}\left(c_{l}\right)\right)\right) \\
& +h^{\prime}(\cdot)\left(N_{l} \int_{c_{l}} x \phi_{l}(x) d x+N_{n} \int_{c_{n}} x \phi_{n}(x) d x\right)=0
\end{aligned}
$$

and

$$
g\left(c_{l}\left(N_{n}, N_{l}\right), c_{n}\left(N_{n}, N_{l}\right), N_{n}, N_{l}\right)=\bar{N}-N_{l}\left(1-\Phi_{l}\left(c_{l}\right)\right)-N_{n}\left(1-\Phi_{n}\left(c_{n}\right)\right)=0
$$

\footnotetext{
${ }^{30}$ Recall that $\bar{N}$ is assumed to be fixed.
} 
Using the Implicit Function Theorem, we can show that

$$
\frac{\partial c_{l}}{\partial N_{n}}=\frac{f_{c_{n}}^{\prime} g_{N_{n}}^{\prime}-g_{c_{n}}^{\prime} f_{N_{n}}^{\prime}}{f_{c_{l}}^{\prime} g_{c_{n}}^{\prime}-g_{c_{l}}^{\prime} f_{c_{n}}^{\prime}}
$$

where

$$
\begin{aligned}
f_{c_{n}}^{\prime} & =-h^{\prime}(\cdot) N_{n} c_{n} \phi_{n}\left(c_{n}\right)-h(\cdot) \\
g_{N_{n}}^{\prime} & =-\left(1-\Phi_{n}\left(c_{n}\right)\right) \\
g_{c_{n}}^{\prime} & =N_{n} \phi_{n}\left(c_{n}\right) \\
f_{N_{n}}^{\prime} & =h^{\prime}(\cdot) \int_{c_{n}} x \phi_{n}(x) d x \\
f_{c_{l}}^{\prime} & =h(\cdot)-h^{\prime \prime}(\cdot) N_{l} \phi_{l}\left(c_{l}\right)\left(N_{l} \int_{c_{l}} x \phi_{l}(x) d x+N_{n} \int_{c_{n}} x \phi_{n}(x) d x\right)-N_{l} \phi_{l}\left(c_{l}\right)\left(h^{\prime}(\cdot)\left(2 c_{l}-c_{n}\right)\right) \\
g_{c_{l}}^{\prime} & =N_{l} \phi_{l}\left(c_{l}\right)
\end{aligned}
$$

The denominator is:

$$
\left[h(\cdot)-h^{\prime \prime}(\cdot) N_{l} \phi_{l}\left(c_{l}\right)\left(N_{l} \int_{c_{l}} x \phi_{l}(x) d x+N_{n} \int_{c_{n}} x \phi_{n}(x) d x\right)-N_{l} \phi_{l}\left(c_{l}\right)\left(h^{\prime}(\cdot)\left(2 c_{l}-c_{n}\right)\right)\right] N_{n} \phi_{n}\left(c_{n}\right)+
$$

$N_{l} \phi_{l}\left(c_{l}\right)\left[h^{\prime}(\cdot) N_{n} c_{n} \phi_{n}\left(c_{n}\right)+h(\cdot)\right]$

which can be rewritten as

$$
\begin{aligned}
& N_{n} \phi_{n}\left(c_{n}\right) h(\cdot)+N_{l} \phi_{l}\left(c_{l}\right) h(\cdot)+2 N_{l} \phi_{l}\left(c_{l}\right) N_{n} \phi_{n}\left(c_{n}\right)\left(h^{\prime}(\cdot)\left(c_{n}-c_{l}\right)\right)- \\
& h^{\prime \prime}(\cdot) N_{l} \phi_{l}\left(c_{l}\right) N_{n} \phi_{n}\left(c_{n}\right)\left(N_{l} \int_{c_{l}} x \phi_{l}(x) d x+N_{n} \int_{c_{n}} x \phi_{n}(x) d x\right) .
\end{aligned}
$$

Since $c_{n}>c_{l}, h(\cdot)>0, h^{\prime}(\cdot)>0$, and $h^{\prime \prime}(\cdot)<0$, all the terms in the expression are positive, so the sign of denominator is positive.

Now consider the numerator:

$$
\left[h^{\prime}(\cdot) N_{n} c_{n} \phi_{n}\left(c_{n}\right)+h(\cdot)\right]\left[1-\Phi_{n}\left(c_{n}\right)\right]-N_{n} \phi_{n}\left(c_{n}\right) h^{\prime}(\cdot) \int_{c_{n}} x \phi_{n}(x) d x
$$


which can be rewritten as:

$$
h^{\prime}(\cdot) N_{n} \phi_{n}\left(c_{n}\right)\left(1-\Phi_{n}\left(c_{n}\right)\right)\left[c_{n}-\frac{\int_{c_{n}} x \phi_{n}(x) d x}{1-\Phi\left(c_{n}\right)}\right]+h(\cdot)\left(1-\Phi\left(c_{n}\right)\right)
$$

The term inside the brackets is negative: the expected value of $x$ conditional on being above the cutoff has to be greater than the cutoff. $h^{\prime}(\cdot) N_{n} \phi_{n}\left(c_{n}\right)\left(1-\Phi_{n}\left(c_{n}\right)\right)$ and $h(\cdot)\left(1-\Phi\left(c_{n}\right)\right)$ are both positive. Thus, $\frac{\partial c_{l}}{\partial N_{n}} \leq 0$ when

$$
h(\cdot) \leq h^{\prime}(\cdot) N_{n} \phi_{n}\left(c_{n}\right)\left[\frac{\int_{c_{n}} x \phi_{n}(x) d x}{1-\Phi\left(c_{n}\right)}-c_{n}\right]
$$

We have used the fact that the Implicit Function Theorem (applied to our first order conditions) states that

$$
\left[\begin{array}{c}
\frac{\partial c_{l}}{\partial N_{n}} \\
\frac{\partial c_{n}}{\partial N_{n}}
\end{array}\right]=-\left[\begin{array}{ll}
f_{c_{l}}^{\prime} & f_{c_{n}}^{\prime} \\
g_{c_{l}}^{\prime} & g_{c_{n}}^{\prime}
\end{array}\right]^{-1}\left[\begin{array}{l}
f_{N_{n}}^{\prime} \\
g_{N_{n}}^{\prime}
\end{array}\right]
$$

Using the fact that that the negative inverse of the square matrix is

$$
-\left[\begin{array}{cc}
f_{c_{l}}^{\prime} & f_{c_{n}}^{\prime} \\
g_{c_{l}}^{\prime} & g_{c_{n}}^{\prime}
\end{array}\right]^{-1}=\frac{1}{f_{c_{l}}^{\prime} g_{c_{n}}^{\prime}-g_{c_{l}}^{\prime} f_{c_{n}}^{\prime}}\left[\begin{array}{cc}
-g_{c_{n}}^{\prime} & f_{c_{n}}^{\prime} \\
g_{c_{l}}^{\prime} & -f_{c_{l}}^{\prime}
\end{array}\right]
$$

we have

$$
\frac{\partial c_{l}}{\partial N_{n}}=\frac{f_{c_{n}}^{\prime} g_{N_{n}}^{\prime}-g_{c_{n}}^{\prime} f_{N_{n}}^{\prime}}{f_{c_{l}}^{\prime} g_{c_{n}}^{\prime}-g_{c_{l}}^{\prime} f_{c_{n}}^{\prime}}
$$

as we claimed earlier in the proof. 


\section{B Supporting Figures and Tables}

Figure B1: Trends in Average SAT Scores, Classes of 2000-2017

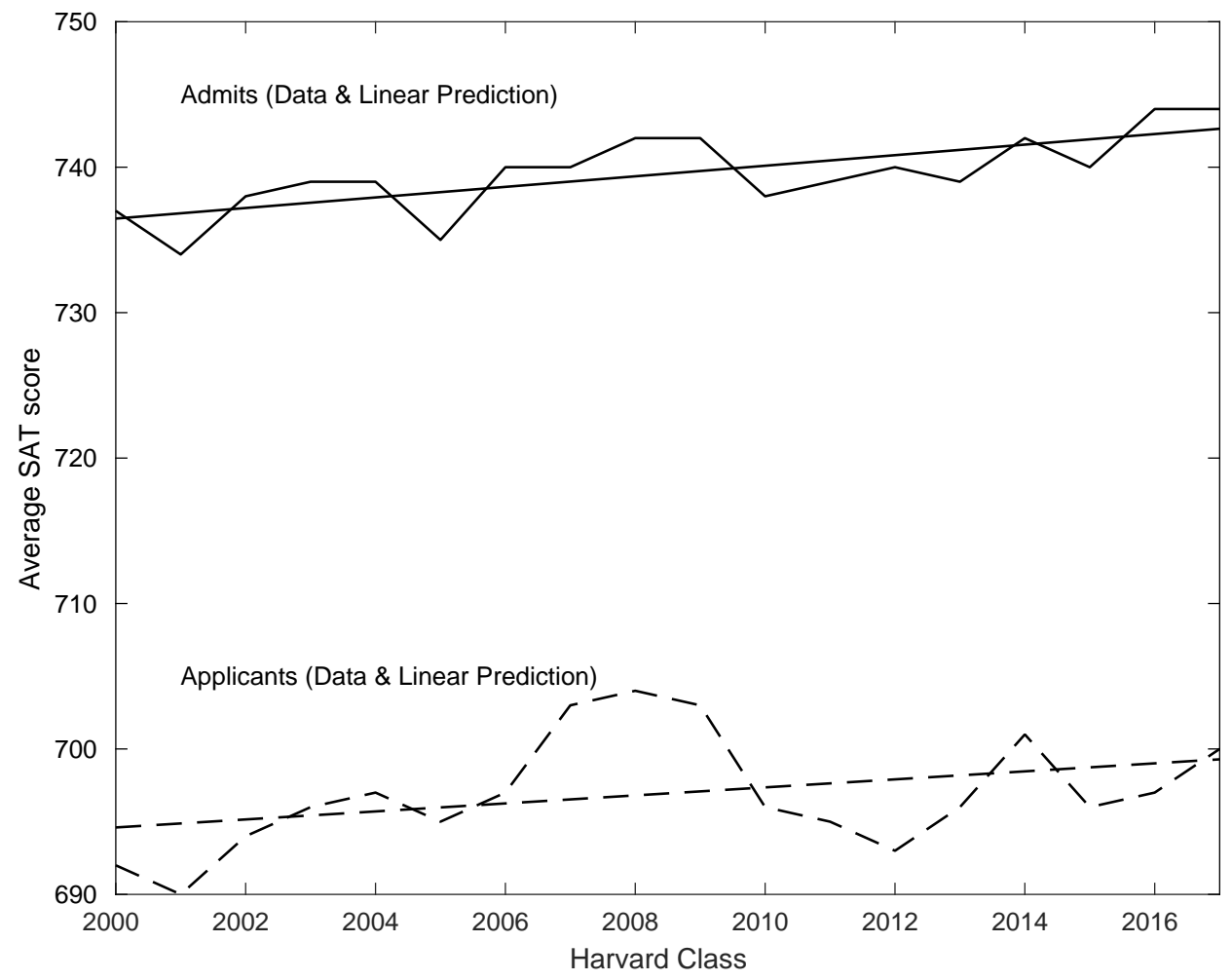

Note: Includes only domestic applicants.

Source: Authors' calculations from SFFA v. Harvard Trial Exhibit DX 042. 
Figure B2: Trends in LA Share of Applications and Admits for Whites Only

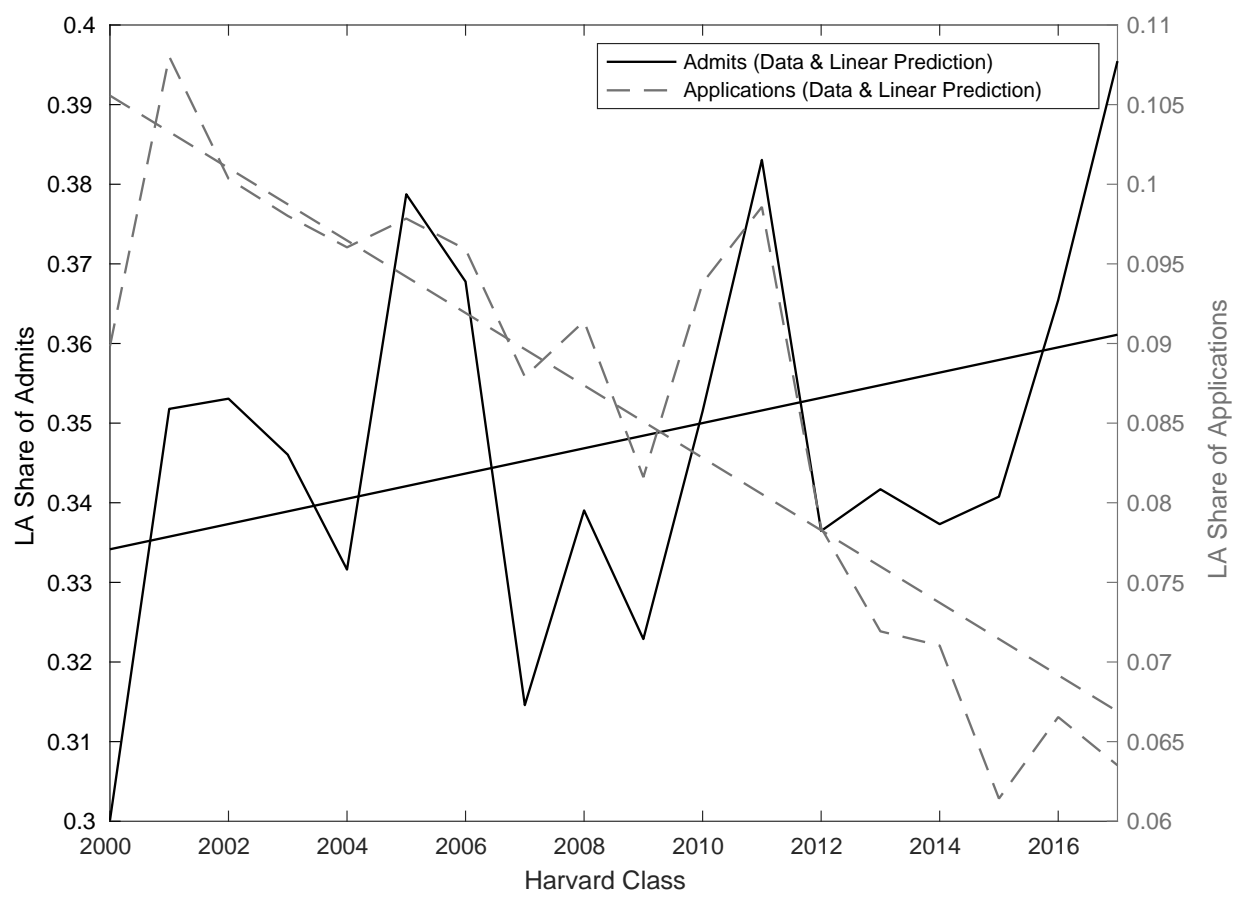

Note: Domestic applicants only.

Source: Authors' calculations from SFFA v. Harvard Trial Exhibit DX 042. 
Table B1: Domestic Applicants, Admits, and Matriculants by Class

\begin{tabular}{cccccccc}
\hline & \multicolumn{3}{c}{ Legacy and Athlete } & & \multicolumn{2}{c}{ Non-Legacy and Non-Athletes } \\
\cline { 2 - 3 } Year & Applicants & Admits & Matriculants & & Applicants & Admits & Matriculants \\
\hline 2000 & 989 & 409 & 324 & & 14,841 & 1,547 & 1,203 \\
2001 & 1,039 & 485 & 397 & & 13,242 & 1,533 & 1,130 \\
2002 & 1,026 & 492 & 411 & & 13,559 & 1,478 & 1,143 \\
2003 & 1,074 & 485 & 409 & & 14,682 & 1,455 & 1,117 \\
2004 & 1,094 & 491 & 419 & & 15,108 & 1,462 & 1,116 \\
2005 & 1,101 & 540 & 444 & & 15,267 & 1,414 & 1,067 \\
2006 & 1,155 & 515 & 437 & & 15,887 & 1,405 & 1,060 \\
2007 & 1,086 & 444 & 392 & & 17,049 & 1,490 & 1,105 \\
2008 & 1,038 & 464 & 402 & & 15,864 & 1,469 & 1,086 \\
2009 & 1,034 & 433 & 381 & & 18,377 & 1,486 & 1,104 \\
2010 & 1,081 & 473 & 418 & & 18,240 & 1,468 & 1,114 \\
2011 & 1,121 & 476 & 419 & & 17,974 & 1,439 & 1,073 \\
2012 & 1,079 & 451 & 405 & & 21,877 & 1,531 & 1,080 \\
2013 & 1,094 & 472 & 427 & & 23,556 & 1,505 & 1,069 \\
2014 & 1,095 & 454 & 400 & & 24,388 & 1,557 & 1,104 \\
2015 & 1,069 & 450 & 399 & 27,867 & 1,518 & 1,068 \\
2016 & 1,114 & 449 & 409 & 26,861 & 1,411 & 1,070 \\
2017 & 1,094 & 488 & 437 & 27,512 & 1,349 & 1,037 \\
\hline
\end{tabular}

Note: Domestic applicants only.

Source: Authors' calculations from SFFA v. Harvard Trial Exhibit DX 042. 
Figure B3: Application Trends at Harvard and Other Elites

(a) Total Applications

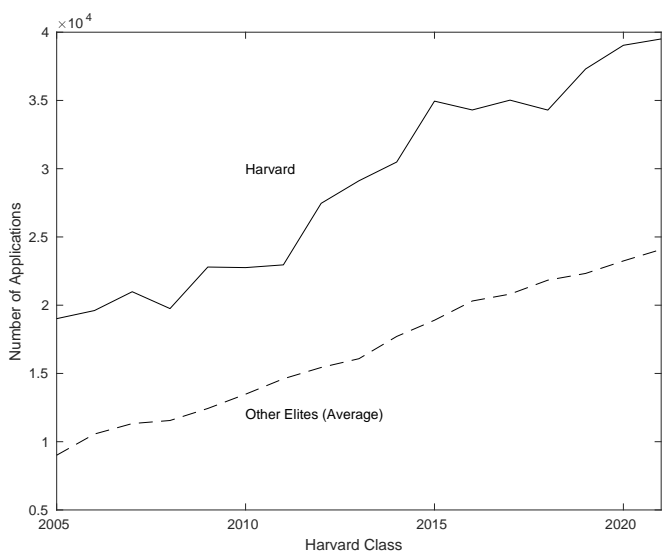

(b) Application Growth

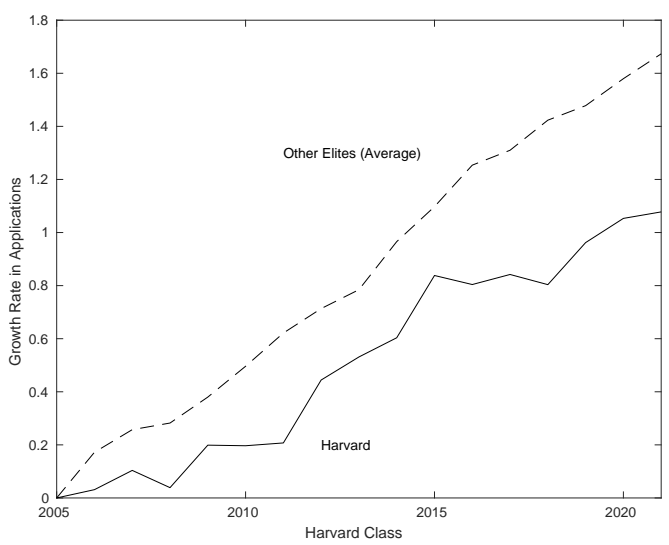

Notes: Panel (a) lists, by year, the total number of applications submitted to Harvard, compared to the total number of applications submitted to Other Elites divided by the number of Other Elite universities. Panel (b) lists growth rates based on the numbers presented in Panel (a).

Other Elites include the following: Amherst College, Caltech, Carnegie Mellon, Columbia, Cornell, Dartmouth, Duke, Harvey Mudd, Johns Hopkins, MIT, Northwestern, Pomona College, Princeton, Rice, Stanford, Swarthmore, Penn, Williams, and Yale. These were chosen because they are 4-year public and private universities that have a 75 th percentile math SAT score greater than or equal to 750 between the years of 2001 and 2017, and because they are not missing more than one year of SAT scores or application totals.

Source: Authors' calculations from SFFA v. Harvard Trial Exhibit DX 042 and US National Center for Education Statistics' Integrated Postsecondary Education Data System (IPEDS). 
Figure B4: Application Trends at Harvard and Other Ivies

(a) Total Applications

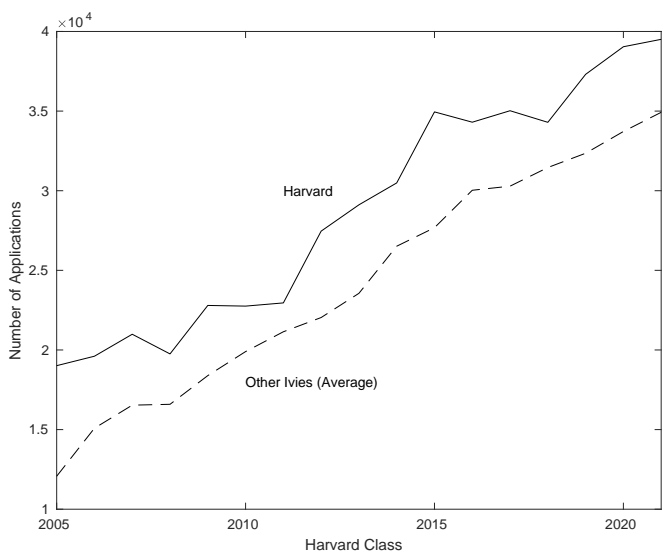

(b) Application Growth

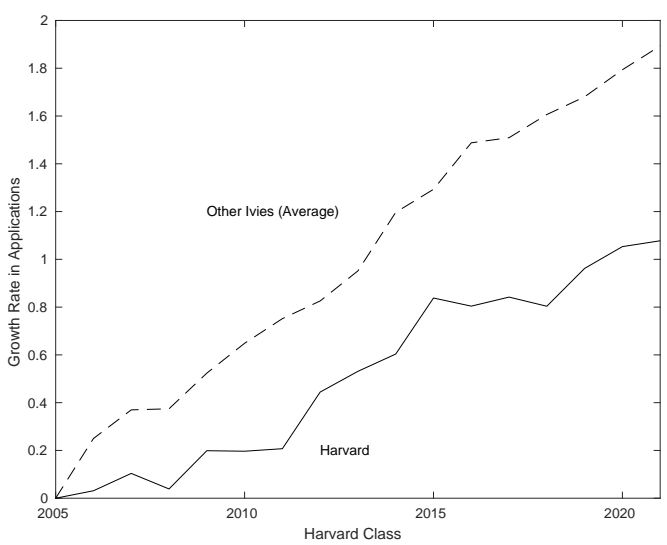

Notes: Panel (a) lists, by year, the total number of applications submitted to Harvard, compared to the total number of applications submitted to other Ivy League institutions divided by the number of other Ivies. Panel (b) lists growth rates based on the numbers presented in Panel (a).

Other Ivies include Columbia, Cornell, Dartmouth, Princeton, Penn, and Yale. Brown is excluded due to incomplete data.

Source: Authors' calculations from SFFA v. Harvard Trial Exhibit DX 042 and US National Center for Education Statistics' Integrated Postsecondary Education Data System (IPEDS). 